\title{
Bartolomé de Mesa Túpac Yupanqui: trayectoria de un comerciante de la élite indígena limeña (1774-1810)
}

\section{Bartolomé de Mesa Túpac Yupanqui: trajectory of a trader of the Lima's indigenous elite (1774-1810)}

\section{Teresa Vergara Ormeño ${ }^{1}$}

Pontificia Universidad Católica del Perú

Universidad de Lima

\section{Resumen}

Análisis de la trayectoria de Bartolomé de Mesa Túpac Yupanqui, miembro de la élite comercial limeña de ascendencia indígena, en un periodo de grandes cambios que van desde la implementación de las reformas borbónicas y sus consecuencias en la economía limeña, pasando por la rebelión de Túpac Amaru II hasta la invasión francesa de España y el surgimiento de juntas de gobierno en diversos territorios americanos. $\mathrm{Su}$ estudio permite ver las similitudes y diferencias entre su accionar y el de cualquier comerciante espańol o criollo de su misma categoría y el proceso de cambio de su posición política, que pasó de la total fidelidad a la Corona espańola, pues

1 Docente del Departamento de Humanidades - Sección Historia. Contacto: teresa.vergara@pucp.edu.pe 
fue el principal financista de las fiestas indígenas en honor de Carlos IV que se realizaron en Lima en 1790, a participar activamente en las conspiraciones que ocurrieron en la ciudad con el objetivo de conseguir una mayor autonomía para las elites locales. Se vinculó con Mateo Silva, abogado limeño, principal organizador de las reuniones secretas autonomistas en las que Bartolomé de Mesa participó activamente y por las que fue encarcelado y acusado de conspirador.

Palabras clave: comerciantes mestizos, rebelión de Túpac Amaru II, siglo XVIII, Lima

\section{Abstract}

Analysis of the trajectory of Bartolomé de Mesa Túpac Yupanqui, a member of Lima's trader elite of indigenous descent, in a period of great changes that go from the implementation of the Bourbon reforms and their consequences in the Limeña economy, passing through the rebellion of Túpac Amaru II until the French invasion of Spain and the emergence of government boards in several American territories. His study allows us to see the similarities and differences between his actions and that of any Spanish or Creole merchant of the same category and the process of changing his political position, which went from total loyalty to the Spanish Crown, because he was the main financier of the indigenous festivities in honor of Charles IV that were held in Lima in 1790, to participate actively in the conspiracies that occurred in the city with the aim of achieving greater autonomy for local elites. He was linked to Mateo Silva, a lawyer from Lima, main organizer of the secret autonomist meetings in which Bartolomé de Mesa actively participated and for which he was imprisoned and accused of conspiracy. 
Keywords: mestizo traders, Túpac Amaru II rebellion, XVIII century, Lima

El 20 de mayo de 1793, antes de partir para Quito donde residiría por un largo tiempo, D. Bartolomé de Mesa Túpac Yupanqui hizo relación impresa de sus méritos y servicios al superior gobierno. Declaró que era vecino de Lima, comerciante en la clase de almacenero, segundo comandante de las compañías de naturales de la capital y sus contornos con el grado de sargento mayor y descendiente de los emperadores incas del Perú (AGN GO-BI5 L. 175 Exp. 926 1805). ${ }^{2}$

Bartolomé de Mesa, como él mismo lo indica, era un comerciante almacenero. Es decir, poseía un almacén en la capital donde acumulaba grandes volúmenes de productos de la tierra y de importaciones traídas desde España que luego distribuía en distintas regiones del virreinato a través de sus factores o de comerciantes itinerantes que le compraban las mercancías al crédito. ¿Fue su caso excepcional o es posible pensar que hubo otros miembros de la elite indígena dedicados al comercio de importación?

Los trabajos dedicados al estudio de los comerciantes limeńos durante el periodo que abarca este artículo se basan en la trayectoria de comerciantes espańoles tanto peninsulares como criollos (Parrón Salas, 1984; Suárez Espinoza, 1995, 2001; Mazzeo de Vivó, 1994, 1999, 2012). Los estudios sobre co-

2 En 1795, declaró y probó ser descendiente de Alonso Tito Atauchi, hijo del inca Huayna Cápac (AGI Secretaria de Guerra 7104, Exp. 27 citado en Alaperrine-Bouyer, 2007, p. 284). 
merciantes mestizos o indígenas, como es el caso de Bartolomé de Mesa, son prácticamente inexistentes, lo que podría indicar que estamos ante un caso probablemente excepcional. Pero si tomamos en cuenta que desde las primeras décadas del siglo XVIII las élites indígenas tenían mayor participación en la burocracia colonial, se podría señalar que la falta de estudios responde más bien al hecho de que los comerciantes indígenas no llegaron a ocupar las más altas posiciones en el Tribunal del Consulado, por lo que no habrían llamado la atención de los especialistas. Un documento del consulado limeño fechado en 1826 puede ser útil para tener una idea de la posición que ocupaba Bartolomé de Mesa en la jerarquía de comerciantes limeños. El documento muestra que de acuerdo con el volumen de dinero que movía un comerciante, le correspondía una posición en el interior del tribunal. En el caso de Bartolomé de Mesa, llegó a mover alrededor de 50,000 pesos en su periodo de mayor crecimiento comercial, lo que lo clasificaba como un comerciante almacenero de segundo orden. Esta pudo ser una de las razones por las que no logró acceder a posiciones de mayor poder en el Tribunal del Consulado, lo que lo hace poco visible para los interesados en el estudio de los grandes comerciantes coloniales. Desde esta perspectiva, el caso de Bartolomé de Mesa no es excepcional, hubo otros indios de la élite dedicados a la actividad comercial, lo que falta son más estudios y una mirada distinta de la sociedad colonial de las 108 últimas décadas del siglo XVIII. ${ }^{3}$

3 Ilario Gómez y Ramón Landaburu fueron otros dos comerciantes indígenas dedicados a la venta de productos de Castilla. Ambos pertenecían a la red de comerciantes de Bartolomé de Mesa y participaron junto con él como comisarios en la celebración que los indios ofrecieron en honor a Carlos IV en 1790. Mariano Carranza fue otro indio dedicado a la actividad comercial, aunque con un caudal bastante inferior al de Bartolomé 
El objetivo de este trabajo es analizar la trayectoria de Bartolomé de Mesa Túpac Yupanqui, miembro de la élite comercial limeña de ascendencia indígena, en un periodo de grandes cambios que van desde la implementación de las reformas borbónicas y sus consecuencias en la economía limeña, pasando por la rebelión de Túpac Amaru II hasta la invasión francesa de España y el surgimiento de juntas de gobierno en diversos territorios americanos. El estudio de la trayectoria de un comerciante de la élite indígena permite ver las similitudes y diferencias entre su accionar y el de cualquier comerciante español o criollo de su misma categoría. Por otro lado, el estudio de un personaje como Bartolomé de Mesa muestra el proceso de cambio de su posición política, que pasó de la total fidelidad a la Corona española, pues fue el principal financista de las fiestas indígenas en honor de Carlos IV que se realizaron en Lima en 1790, a participar activamente en las conspiraciones que tuvieron lugar en la ciudad con el objetivo de conseguir una mayor autonomía para las élites locales. Los trabajos de Mazzeo de Vivó han senalado la importancia de las relaciones que los comerciantes establecían con sus pares o personas destacadas en el ámbito no solo mercantil, sino político y militar para tener éxito en su actividad económica. Bartolomé de Mesa no fue ajeno a esa práctica. Su estrecha vinculación con comerciantes españoles se evidencia en la cercanía que llegó a tener con Toribio

de Mesa. Había nacido también en el valle del Mantaro, pero tenía un origen diferente, era un indio del común que con la venta de productos de la tierra logró obtener ingresos importantes que invirtió en la comercialización de productos de Castilla. Sobre la actividad comercial de Gómez, Landaburu y Carranza, véanse los protocolos del notario Pedro Lumbreras en el Archivo General de la Nación del Perú. Para información sobre Carranza, véase también Cosamalón Aguilar (1999). 
Silva, por cuyo intermedio habría conocido a Mateo Silva, abogado limeño hijo del anterior, principal organizador de las reuniones secretas autonomistas en las que Bartolomé de Mesa participó activamente y por las que fue encarcelado y acusado de conspirador.

La trayectoria de Bartolomé de Mesa puede dividirse en tres etapas. La primera, que va de 1774 hasta 1781, corresponde a sus inicios en la venta de productos de la tierra. La segunda etapa, de 1781 a 1793, corresponde a un periodo de crecimiento económico en el que se dedica al comercio de productos de Castilla. Esta etapa coincide con el lapso de mayor estabilidad del comercio internacional, entre 1784 y 1796, en el cual se aplicaron las reformas borbónicas, en especial el Reglamento del Libre Comercio, que permitió la expansión comercial a mayor escala entre América y España. ${ }^{4}$ En ese periodo se vivió en el virreinato un ambiente de gran desconfianza de las autoridades con respecto al comportamiento de las poblaciones indígenas, producto de la rebelión de Túpac Amaru II. La última etapa de Bartolomé de Mesa abarca de 1793 a 1810, periodo bastante complicado tanto por los vaivenes de su actividad comercial y de su vida afectiva, como por las decisiones políticas que tomó. En esa etapa trasladó su actividad comercial a Quito, donde alcanzó gran éxito económico, pero a costa del deterioro de su vida familiar. En 1806, regresó a Lima, obligado por las autori-

110 dades para que cumpla con sus obligaciones maritales y asumir su responsabilidad como miembro de las milicias ante la guerra con Inglaterra, lo que le ocasiona grandes pérdidas económicas. Cuando intentaba la recuperación de su negocio, llegaron a la

4 Sobre las reformas borbónicas y el impacto en el comercio limeño, véanse los estudios de Mazzeo de Vivó $(1994,1999)$ al igual que los de Parrón Salas (1984). 
ciudad las noticias de la invasión francesa en la Península y del estallido rebelde en Quito en 1809. En setiembre del mismo año, un mes después de lo sucedido en Quito, Bartolomé fue acusado de formar parte de un grupo que buscaba duplicar en Lima las acciones de los rebeldes quiteños. Junto con los otros miembros del grupo fue apresado y enviado a la cárcel de corte, donde fue acusado de mantener correspondencia con los rebeldes de Quito. Bartolomé nunca abandonó la cárcel, poco tiempo después de su arresto murió cuando le estaban tomando sus declaraciones. La última etapa de la vida de Bartolomé de Mesa coincidió con el periodo de dificultades económicas y políticas para Espańa y sus colonias, que abarcó de 1797 a 1810. Los hechos políticos y económicos de ese periodo, como la guerra con Inglaterra, la utilización de las embarcaciones de neutrales y la invasión napoleónica a España en 1808 desarticularon totalmente el comercio intercontinental y dieron un giro total a la vida de este comerciante indígena.

\section{Descendiente de los incas, comerciante almacenero, sargento mayor de milicias y vecino de Lima}

Para entender la trayectoria de Bartolomé de Mesa Túpac Yupanqui como comerciante, es necesario conocer acerca de su persona y de la situación en la que se encontraban los miembros de la élite indígena limeña en el último tercio del siglo XVIII. Bartolomé había nacido en San Jerónimo, pueblo de indios situado en el valle del Mantaro. ${ }^{5}$ No se tiene informa-

5 El hecho de que Bartolomé de Mesa no hubiese nacido en el Cuzco, si bien no cuestiona el hecho de que sea miembro de la élite inca, evidencia que forma parte de una élite inca regional y, por lo tanto, segunda en términos de cómo podría ser considerado por un miembro de la élite inca de la ciudad del Cuzco. Sin embargo, los Túpac Inca Yupanqui de San 
ción sobre la fecha de su traslado a Lima, pero se sabe que en 1774 ya se encontraba en la ciudad dedicado a la venta de productos de la tierra. En 1781, contrajo matrimonio con Bernarda Tello de Guzmán, vecina de Lima, ${ }^{6}$ pero originaria de su mismo pueblo. ${ }^{7}$ Bernarda era una mujer de buena posición económica, como se puede notar por el monto de su dote ascendente a 30.019 pesos en alhajas, muebles y ropa (AGN CA-JO1 L. 153 Exp. 2821 1807). Como era usual, Bartolomé utilizó parte de la dote de su esposa para ampliar sus actividades comerciales y llegó a tener un éxito bastante considerable, considerando los montos de la mercadería que entregaba a otros comerciantes, los que podían ascender hasta los 13.000 pesos, como se señala en la escritura hecha por don Manuel de Seballos fechada en mayo de 1795 en la ciudad de Quito. Años después, cuando la relación entre ambos era mala, Bernarda señaló que Bartolomé no llevó ningún dinero al matrimonio y que todo lo que consiguió fue a partir de su dote (AGN GO-BI 5 L. 186 Exp. 11051810 f. 29v).

Jerónimo eran indios principales, cuyo poder devenía justamente de la conquista de la región por Túpac Inca Yupanqui. La importancia de este linaje se mantuvo durante todo el periodo colonial y pasó al periodo republicano, porque tan tarde como en 1907, Teodomiro Gutiérrez Cuevas denuncia los abusos del gobernador de San Jerónimo de apellido Túpac Yupanqui (Arroyo Reyes, 2005, p. 92). Sobre la conquista inca del valle del Mantaro, véase Cieza de León (2005, pp. 405-406, 420).

6 Bernarda había llevado dote al matrimonio y tenía dinero que prestaba con interés. En 1806 presentó una demanda a la viuda de Gabriel Guerra, indio de Jauja que había fallecido en el hospital de Santa Ana, para que le pague 1500 pesos de un préstamo de 1000 pesos al $6 \%$ anual de interés que le había hecho a su esposo y por los que había puesto como hipoteca dos casas y una pulpería (AGN CA-JO1 L. 150 Exp. 2723 1806).

7 La información del matrimonio entre Bartolomé y Bernarda se ubicó en FamilySearch.org. 
Bartolomé de Mesa era mestizo y así lo muestra su retrato pintado por el reconocido pintor José Vásquez en 1790. Él se identificaba como miembro de la nación índica. ${ }^{8}$ La razón se relaciona con los espacios de poder que las élites indígenas habían logrado alcanzar, en especial la élite de la ciudad de Lima durante el siglo XVIII. Los miembros de la élite indígena limeña habían logrado que se hiciese efectiva la real cédula de 1697, conocida como la "cédula de los honores", otorgada a la nación índica por el último de los Habsburgo. Esta real cédula les permitía acceder a posiciones de poder dentro de la esfera civil y religiosa anteriormente reservadas para los españoles. Desde la década de 1730 podían ser ordenados sacerdotes, a partir de 1763 consiguieron ser nombrados procuradores de naturales y años más tarde comenzaron a ingresar cada vez en mayor número a la Universidad de San Marcos para seguir estudios de teología y leyes e ingresar como catedráticos en la universidad. Está claro que Bartolomé de Mesa podía obtener mayor reconocimiento en la sociedad colonial si se identificaba como miembro de la nación índica que si lo hacía como mestizo. Para aspirar a los derechos que la "cédula de los honores" otorgaba a los miembros de la nación índica se exigía como requisito ser puro de sangre o indio por sus cuatro costados. El ser mestizo, aunque se fuese rico como Bartolomé de Mesa, no proporcionaba el mismo prestigio que identificarse como miembro de la nación índica, con mayor razón si se era parte de la élite indígena.

8 El término nación índica corresponde a una definición escolástica (aristotélico-tomista) de cuerpo de nación, que se refiere al estatus socio-cultural y jurídico del conjunto de la población indígena americana. En los hechos, aparece circunscrito a espacios territoriales concretos como el virreinato del Perú, donde se habla de una nación española, una nación índica y una nación etíope o afroperuana correspondientes a los tres grupos étnicos del virreinato. 
Identificarse como miembro de la nación índica no era solo de nombre, Bartolomé de Mesa se consideraba realmente parte de ese grupo étnico. ${ }^{9}$ Por pertenecer a la élite indígena de la ciudad, se encontraba dentro de los miembros dirigentes de ese cuerpo social y pudo llegar a actuar en 1790 como su benefactor.

Con ocasión de la subida al trono de Carlos IV, Bartolomé de Mesa preparó una serie de actos en los que tomarían parte tanto las élites como el común de indios de la ciudad de Lima para celebrar el ascenso al trono del nuevo rey, celebración que duró del 7 al 9 de febrero. Bartolomé de Mesa jugó un papel central en esa celebración, pues no solo la organizó, sino que corrió con los gastos de los cuatro carros alegóricos que se presentaron y contribuyó con cuatrocientos cincuenta pesos para cubrir el costo de la corrida de toros que el común de indios no había logrado reunir. Para guardar memoria de la celebración, Bartolomé de Mesa solicitó a don Esteban de Terralla y Landa escribir el relato de las celebraciones y pagó el costo de la publicación que tituló El sol en el mediodía: año feliz, júbilo particular con que la nación indica de esta muy noble ciudad de Lima solemnisó la exaltación al trono de ntro. augustísimo monarca el señor don Carlos IV: En los días 7, 8 y 9 de febrero de 1790. El texto se imprimió en la Casa Real de Niños Expósitos y subraya la fidelidad de la nación índica a la Corona espańola y, en particular, la de Bartolomé de Mesa

114 que no escatimó esfuerzos ni dinero para rendir homenaje y demostrar su fidelidad al nuevo rey. Es importante tener en cuenta que estas acciones ocurrieron en un momento com-

9 En los dos testamentos que otorga se identifica como miembro de la nación índica (AGN PN No 582 1784-85 f. 111v-112v; No 5871794 f. 74v-78r). El segundo testamento lo otorgó el 1 de abril de 1794, poco antes de su viaje a Quito. 
plicado para las élites indígenas del virreinato. La rebelión de Túpac Amaru II y diversos levantamientos indígenas habían tenido lugar en numerosas regiones a lo largo de toda la década anterior, lo que generó un clima de profunda desconfianza de las autoridades coloniales con respecto a la fidelidad de las poblaciones indígenas. En ese contexto, era especialmente importante dejar constancia de la fidelidad de la nación índica residente en Lima a través no solo de la participación en las celebraciones, sino también dejando un texto que perennizara ese momento y en el que quedase por escrito los sentimientos de la nación índica hacia el nuevo monarca. Sentimientos que se hacen explícitos en la conclusión del texto:

Estas son las señales con que la nación indica ha demostrado a su Majestad su amor y jubilo en su feliz coronación. Ella quisiera dar pruebas mas activas de su zelo, de su gratitud y sus finezas; pero la grandeza de estas, su mismo tamańo hace imposible el desempeño. Un amor sin limites, una fe que no es ceñida, una voluntad que se dilata sin que ningunos términos la opriman; son objetos inexplicables (...) (Terralla y Landa, 1790).

El financiamiento de las celebraciones y del texto, como el cuidado de cada detalle tenían para Bartolomé de Mesa una importancia capital porque era la manera de demostrar la fidelidad de los indios de Lima -élite y comunes-, es decir, de la nación índica de la ciudad en su conjunto, a la Corona española.

Desde una perspectiva más individual, estas acciones debían permitirle alcanzar sus metas personales. A inicios de diciembre de 1791, le otorgó poder a don Antonio Porcel y a don Francisco Sarmiento, "vecinos de la Villa y Corte de Madrid y agentes del número de Indias", para que en su nombre se presenten ante el rey Carlos IV y el Consejo de Indias 
(...) pidiendo que en mi remuneración de los méritos y servicios que tengo hechos a su majestad me haga quales quiera mercedes y gracias de las que confiere para estos reinos, las que conseguidas, aceptarán o renunciarán, con el respecto devido según les pareciere, pidiendo se libren las respectivas reales cédulas, las que me remitirán por uno, dos o más duplicados en mas promptas y seguras conductas que el tiempo ofrecieren, cuyo particular presentaran, los memoriales suplicas, y representaciones que sean fuese servido librarme (...). (AGN PN No 585 1790-91 f. 520r).

Aprovechando este hecho, el cabildo de indios de la ciudad le otorgó un poder para que gestionase en Madrid todas las "pretensiones, útiles y benéficas a la nación yndica" (AGN Fáctica 1791). La estrecha relación entre Bartolomé y los miembros del cabildo de indios de la ciudad quedó nuevamente en evidencia. Pocos años después, en 1795, decidió solicitar una nueva merced, esta vez ante el virrey, para que se le conceda el grado de coronel de milicias de infantería de los naturales de Lima (Alaperrine-Bouyer, 2007, p. 284). Él poseía un grado alto en la milicia, pero aspiraba a obtener el más alto, que era el de coronel. Este grado le otorgaba el derecho al tratamiento de señoría, por lo que era muy codiciado entre los comerciantes como signo de su pertenencia a las élites (Mazzeo de Vivó, 1994, p. 81; O’Phelan, 1995, p. 82). Es posible que Bartolomé de Mesa considerara que con ese grado podría alcanzar una posición de poder dentro del Tribunal del Consulado. En esa institución, los priores y cónsules eran todos miembros de la nobleza española y ostentaban el grado más alto en las milicias. Él era miembro de la nobleza indígena y si lograba ser nombrado coronel estaría a la misma altura que los comerciantes españoles, entre los que rotaban los cargos de poder en el Tribunal del Consula- 
do. ${ }^{10}$ Sin embargo, las cosas no resultaron como él esperaba y su solicitud fue denegada.

La negativa se basó en las consideraciones expuestas por Gabriel de Avilés y del Fierro, futuro virrey del Perú (18011806), que en ese momento se desempeñaba como gobernador del presidio y plaza fuerte del Callao. Avilés descalificó a Bartolomé de Mesa al señalar:

(...) Mesa aunque se llame y sea comerciante, es un mercader en la práctica, que vende géneros en su tienda y sería cosa muy rara que condecorado con un grado a quien V.M. distingue tanto, se viese después detrás de su mostrador abatido baxando piezas de efectos y vareándolas a la voluntad del negro, del zambo y del mulato que van a comprarle (...)". (AGI Secretaria de Guerra 7104 Exp. 27 citado en Alaperrine-Bouyer, 2007, p. 284).

¿Por qué Avilés se expresó de manera tan dura y poco veraz sobre la posición de Bartolomé de Mesa? Es muy probable que Avilés se encontrase dentro del grupo de los españoles que consideraba negativo para el mantenimiento del poder de la Corona española que las élites indígenas tuviesen mayor espacio de poder, principalmente luego de las rebeliones indígenas que habían azotado el virreinato. Avilés había tenido participación central en la derrota sufrida por los rebeldes en el sur. Había formado parte del ejército que derrotó a Túpac

10 Es importante recordar que la elite indígena limeña había logrado en 1763 que se hiciese efectiva la "cédula de los honores", que disponía que los nobles indígenas pudiesen ocupar cualquier puesto en la administración colonial para el que estuviesen preparados. Bartolomé de Mesa, como otros miembros de la élite indígena, estaban dispuestos a que se cumpliese la real cédula que consideraban reconocía la condición de igualdad entre ambas noblezas: la española y la indígena. 
Amaru en 1780 y había estado al mando del que derrotó a Diego Cristóbal Túpac Amaru y Pedro Vilca Apaza dos años después (Tauro del Pino, 1966, t. I, pp. 139-140). Es muy posible que Avilés tuviese una opinión negativa de las élites indígenas, especialmente de aquellos que se identificaban como descendientes de los incas. Pero en este caso, el trato de Avilés parece que tuvo que ver con la actitud señorial del mismo Bartolomé de Mesa. Como se mencionó, era un indio rico, ilustrado y conocedor de los derechos que la Corona española había otorgado a los miembros de la nobleza indígena. Como hombre de su época, tenía una visión estamental de la sociedad; para él la sociedad no estaba dividida entre españoles e indios, sino entre nobles y comunes. Los nobles indígenas eran nobles por derecho, por descender de los antiguos señores de la tierra y, por lo tanto, con los mismos derechos y preeminencias reservadas a sus pares españoles. Alaperrine-Bouyer llega a una conclusión similar sobre la orgullosa actitud de Bartolomé de Mesa al analizar las gestiones que realizó para que su sobrino ingrese al colegio de nobles americanos de Granada (2007, p. 290). La actitud de Bartolomé de Mesa, la misma que se señala distinguía a Túpac Amaru II, debió ser chocante para muchos españoles y criollos que se consideraban superiores por razones étnicas. Es probable que la actitud de Bartolomé de Mesa le recordase a Avilés la de Túpac Amaru. Por eso no habría dudado en descalificar a Bartolomé de Mesa utilizando un argumento falso. Este hecho, sumado a los problemas económicos que afectaban la actividad comercial en Lima a inicios de la década de los noventa, llevó a Bartolomé de Mesa a trasladar su negocio y residencia a Quito en 1795. Bartolomé viajó solo; su esposa permaneció en Lima y esta situación a la larga deterioró la relación. 


\section{De productos de la tierra a efectos de Castilla: su etapa como comerciante en Lima}

De acuerdo con la documentación, Bartolomé de Mesa inició sus actividades en Lima como comerciante en 1774 (véase el cuadro al final del texto). ${ }^{11}$ En los primeros años de su actividad comercial las deudas de mayor cuantía que contrajo fueron principalmente con sus parientes tanto del lado materno como del paterno. ${ }^{12} \mathrm{Al}$ inicio, Bartolomé se dedicó a la venta de ganado de Castilla, según consta en una escritura que tiene con Agustín de Alfaro, del comercio de Lima e Ica. En octubre de 1774, Bartolomé le había dado de su tienda varios efectos por el valor de 1148 pesos un real y tres cuartillas. Como no le pagó, se hizo una nueva escritura en la que se subió el valor de las mercancías. Bartolomé señaló que de acuerdo con lo que figuraba en sus cuentas, el dinero adeudado correspondía a la venta de terneros de Castilla (AGN R.A. C. C. L. 156 Exp. 421 1787).

A partir de 1781, amplió sus actividades comerciales utilizando, como era usual, parte de la dote de su esposa (AGN GOBI 5 L. 186 Exp. 11051810 f. 29v). ${ }^{13}$ La cantidad de dinero que empezó a mover lo muestra como un hábil comerciante,

11 Pagaré de 276 pesos 11/2 reales a D. Bernardo Durán y Mesa del 29 de marzo de 1774.

12 De 1774 a 1782 entre sus acreedores figuran D. Bernardo Durán y Mesa, D. Carlos Túpac Inca Yupanqui y D. Juan Túpac Inca Yupanqui.

13 "Instrumento de compañía entre el difunto y su hermano don Mariano Meza con declaración de que los 5000 pesos puestos por el primero pertenecen a la dote de su mujer Dońa Bernarda Tello y es otorgado ante Vicente Aizcorbe en enero de 1787" en Inventario de los bienes de Bartolomé de Mesa con fecha 24 de noviembre de 1810 AGN GOB-BI 5 Leg. 186 Exp. 1105 “Dependencias por escrituras” f. 48r- f56v. 
como se aprecia por los montos de la mercadería que entregaba, que ascendía a 13,000 pesos. ${ }^{14}$ Durante este periodo, compró predios urbanos a fin de alquilarlos como una estrategia para diversificar su economía y proteger sus intereses económicos, modalidad ampliamente utilizada por los comerciantes y personas con capacidad para adquirir propiedades. ${ }^{15}$

A fines de 1780, dejó de lado la venta de ganado para comerciar con efectos de Castilla. Parte de su éxito se explica por la amplia red de comerciantes que logró construir a los que abastecía con productos de Castilla y que estos se encargaban de trasladar a todas las regiones del virreinato. Entre ellos se encontraba don Pedro Montalván, originario de Yauyos, a quien en mayo de 1788 le entregó productos por el valor de 816 pesos y 5 reales. En la carta de obligación, Moltalván puso como hipoteca una hacienda de Yauyos llamada Huarca (AGN PN 584 1788-89 f.153-154r). Ese mismo año en el mes de junio, Bartolomé entregó a don Ilario Gómez efectos de Castilla por 737 pesos. Don Ilario era también miembro de la nación índica, residía en Lima y se encargaba de comerciar los productos que le compraba en Huamanga (AGN PN 584 1788-89 f.169v). ${ }^{16} \mathrm{Al}$ mes siguiente, la pareja de esposos compuesta por don Bartolomé Rodríguez y dońa María Castellón dejaron en hipoteca a su pequeño esclavo mulato José Eduardo de 8 años de edad a cambio de los 301 pesos y

1205 reales que le debían por los efectos de Castilla que les había

14 Escritura hecha por don Manuel Zevallos fechada en la ciudad de Quito en mayo de 1795.

15 En 1784, tenía alquilados unos cuartos en el callejón de debajo de los Portales a Pedro Flores (AGN CA-ED3 L. 13 Exp. 1447 1815).

16 Ilario Gómez fue otro de los comisarios en las celebraciones que la nación índica ofreció en honor de Carlos IV en 1790. 
vendido "a precios de plaza corriente", Bartolomé les dio dos meses de plazo para cancelar la deuda (AGN PN 584 178889 f. 24r-v). En agosto, don José Camacho, comerciante limeño, compró en su almacén efectos de Castilla por el valor de 2.227 pesos corrientes. Debido a la magnitud de la deuda contraída, Bartolomé le dio de plazo hasta marzo del año siguiente para cancelar la deuda, lo que efectivamente sucedió, según consta en la escritura. Es probable que de Mesa y Camacho llevasen tiempo haciendo negocios juntos porque este último no dejó ningún bien en hipoteca como garantía de pago de la voluminosa deuda contraída (AGN PN 584 1788-89 f. 211r-v). A finales del mismo mes, don Manuel Beraún, residente de Huánuco, otorgó carta de obligación por 1478 pesos por los efectos de Castilla que le vendió a precio de plata corriente y que se comprometió a cancelar en el plazo de cuatro meses (AGN PN No 584 1788-89 f. 240r). A inicios de octubre los hermanos don Bartolomé, don José y don Francisco Bonavia, que se encontraban de partida para la villa de Chancay, y su socio don Cayetano Espinoza, residentes en Lima, otorgaron carta de obligación por el monto de 1910 pesos y 2 reales comprometiéndose a cancelar la deuda en dos partes, la primera en dos meses y la segunda en 4 meses (AGN PN No 584 1788-89 f. 283v-584r). El 10 del mismo mes don Manuel de Seballos residente en Lima le otorgó carta de obligación por el monto de 2254 pesos y 5 reales por los efectos de Castilla que le había vendido a precio de plata corriente y que se los cancelaría en el plazo de cuatro meses (AGN PN No 584 1788-89 f. 319v). A fines del mismo mes, don Juan y don Mariano Cadenas, residentes en Lima y el primero de partida para Quito, otorgaron carta de obligación por el monto de 1351 pesos y 3 reales por los efectos de Castilla que don Bartolomé les había vendido. Ese mismo mes, don Bartolomé Rodríguez y doña María Cas- 
tellón habiendo cancelado su deuda anterior, le otorgaron una nueva carta de obligación ascendente a 744 pesos y 4 1/2 reales por efectos de Castilla comprometiéndose a cancelar la deuda en dos meses. A inicios del mes de noviembre, pocos días antes que don Mariano Cadenas partiese para Quito, le otorgó junto con su socio don Juan Cadenas carta de obligación por el monto de 1787 pesos y 2 reales por el mismo concepto (AGN PN No 584 1788-89 f. 309r-v, 315v-316r). A mediados del mismo mes, don José Ormachea residente en Lambayeque y de partida para Guadalupe, le otorgó carta de obligación por el monto de 1633 pesos y $71 / 2$ reales por los efectos de Castilla que le había vendido "a buena voluntad" y que se comprometía a pagar en el plazo de tres meses (AGN PN No 584 1788-89 f. 319r). El 19 del mismo mes, don Manuel Porras, residente en Lima y de partida para la villa de Cajamarca, le otorgó carta de obligación por la cantidad de 1456 pesos y 5 1/2 reales que le había prestado a precios corrientes y que se comprometió a devolverle en el plazo de tres meses (AGN PN No 584 1788-89 f. 330r-v). El 6 de diciembre don Justo Larrea, residente en Lima, le otorgó carta de obligación por el monto de 1529 pesos y 5 reales por los efectos de Castilla que le había vendido a precio de plata corriente y que se comprometía a pagar en el plazo de dos meses (AGN PN No 584 1788-89 f. 345r). En enero de 1789 nuevamente los esposos Rodríguez y Castellón le otorgaron otra carta de obligación por 308 pesos y 4 reales por los productos de Castilla que les había vendido a precio de plata corriente y que se comprometieron a pagar en mes y medio (AGN PN No 584 1788-89 f. 204r-v, ${ }^{17}$ f. 281r-283v, f.383r-384v). El 3 de febrero don Gabino del Pozo, vecino

17 Esta escritura no corrió. 
y del comercio de Lambayeque, le otorgó carta de obligación por el monto de 780 pesos y 5 reales por los efectos de Castilla que le había vendido (AGN PN No 584 1788-89 f. 393r-v). Como muestran las actividades reseñadas, a fines de la década de 1780 Bartolomé de Mesa había conseguido establecerse en la ciudad como un comerciante en vías de ascenso que buscaba posesionarse como parte de la élite indígena de la ciudad para reclamar los derechos que la real "cédula de los honores" otorgaba a los miembros de este grupo.

El 1 de abril de 1790, poco años antes de su viaje a Quito, otorgó su segundo testamento y poder para testar. En ese documento se identifica nuevamente como miembro de la nación índica y como "vecino y del comercio de Lima" y señala de manera general que es dueño de "...chacras, casas, huertas, esclavos y otras posesiones...”. En el documento nombra como sus albaceas a don José Rodríguez y a don José de Ruiz, a los que les da poder para testar debido a su partida a la "carrera de Quito". Además, señala que con lo que sobrase de sus bienes se forme una capellanía (patronato libre de la jurisdicción eclesiástica) por el bien de su alma, la de sus hermanos, padres y demás parientes. Nombra como primera patrona y capellana a su hermana dońa María de Mesa y a su fallecimiento, a sus parientes más cercanos (AGN PN No 5871794 f. 74v-78r).

Como se puede ver en el cuadro al final del artículo, en los años siguientes antes de su partida a Quito, Bartolomé continuó realizando sus actividades comerciales, tal como lo había hecho en los años anteriores, pero dedicándose por completo a la venta de efectos de Castilla. Entre sus compradores continuaron antiguos clientes que realizaban compras por montos pequeńos, pero también empezó a tener compras por 
montos más importantes. El 4 de setiembre de 1790, don José Vallejos, vecino y del comercio de la ciudad, le otorgó carta de obligación por el monto de 2288 pesos y 5 1/2 reales por los efectos de Castilla que le vendió a precio de plaza y que se comprometió a pagar en tres meses (AGN PN No 585 1790-91 f. 146v-147r ${ }^{\text {. }}$. El 27 de septiembre don Ramón Landaburu, de ascendencia indígena, vecino y del comercio de la ciudad, le otorgó carta de obligación por el monto de 3571 pesos y 3 reales por los efectos de Castilla que le había vendido y que se comprometió a pagar en el plazo de tres meses (AGN PN No 585 1790-91 f. 161v-162r.). El 30 de octubre Mateo Lamas, residente en Lima y de partida para el Cuzco, le otorgó carta de obligación por el monto de 3644 pesos y 7 reales por "factorage", cantidad que se comprometió a pagar en mes y medio. El 15 de noviembre de 1790 don Carlos Ruiz y don Francisco Suárez, el primero de partida para la ciudad del Cuzco y el segundo habitante en Lima, otorgaron carta de obligación a don Bartolomé por el monto de 1787 pesos y 6 1/4 reales por los efectos de Castilla que les había vendido y que se comprometieron a pagar en el plazo de tres meses (AGN PN No 585 1790-91 f. 193v-194r). El 17 de noviembre de 1790 don Antonio Carvajal residente en Lima y de partida para la ciudad de Arequipa, le otorgó carta de obligación por la cantidad de 5021 pesos y 2 reales (AGN PN No 585 1790-91 f. 196r). De acuerdo con estas escri-

124 turas, entre setiembre y noviembre de 1790, Bartolomé de Mesa logró colocar productos por un valor de 16,314 pesos; había dejado de ser un pequeño comerciante para ubicarse como un exitoso comerciante en ascenso.

Como se ve en el cuadro, iniciada la década de 1790, los negocios de Bartolomé no continuaron creciendo, sino que parecieron haberse estancado, la situación se complicaba, 
además, porque sus deudores no pagaban en el tiempo estipulado. El 1 de junio de 1793, don Cosme Jiménez, residente en Lima y de partida para Pasco, otorgó carta de obligación a don Bartolomé por el monto de 615 pesos y 2 reales por los efectos de Castilla que le había vendido y se comprometió a pagar en cinco meses. Debió cancelar su deuda en diciembre, pero recién lo hizo en febrero de 1794 (AGN PN No 586 1792-93 f. 481 r-v). El 21 de marzo de 1794 don José Alsamora y Ursino otorgó carta de obligación a don Bartolomé por el monto de 1056 pesos y 5 reales por los efectos de Castilla que le vendió y que se comprometió a pagar en cuatro meses (AGN PN No 587 1794-95 f. 66v). En la documentación se señala que don José de Alsamora pagó la deuda contraída en 1792 recién en 1819, pero es probable que se trate más bien la deuda contraída en 1794 , cuando la situación económica se hizo aún más complicada. Esta parece haber sido la última transacción hecha por Bartolomé en Lima.

Ese mismo año, probablemente debido a los problemas económicos que los comerciantes limeños estaban enfrentando como consecuencia de las reformas borbónicas, Bartolomé decidió trasladar su negocio y residencia a la ciudad de Quito para proteger su negocio. Las dificultades que los comerciantes tenían para cancelar su deuda en el tiempo señalado son una muestra del deterioro de la situación económica. De los cinco comerciantes a los que Bartolomé les entregó productos de Castilla en el ańo anterior a su partida, solo dos pagaron a tiempo, los tres restantes se demoraron, en el mejor de los casos varios meses, pero a don José Alsamora y Ursino saldar la deuda le tomó diecisiete años. La crisis de la actividad comercial siguió en aumento en los años siguientes. Los deudores se comprometían a pagar, pero luego no podían 
cumplir su promesa. El caso de Mateo Lamas, conductor de correos, y su mujer Mercedes de la Fuente es ilustrativo. Ambos le adeudaban a Bartolomé 852 pesos y un real y medio, pero solo habían podido pagar 48 pesos. Por lo que le ofrecieron a Manuel Camino, administrador de los bienes de Bartolomé durante su ausencia, que le entregarían una barra de plata, cuyo valor excedía el monto de lo adeudado. Sin embargo, la entrega de la barra de plata no tenía cuando efectuarse. Al parecer, debido a las deudas acumuladas por la pareja, la barra de plata había sido embargada por la Casa de la Moneda. Sobre la difícil situación económica que varios de los comerciantes enfrentaban, Mariana de Mesa, hermana de Bartolomé, afirmaba que debido a la quiebra o muerte de los deudores de su hermano ya se habían perdido 12,000 pesos sin que haya esperanza de recuperarlos (AGN GO-BI 5 L. 186 Exp. 11051810 f. 8r). Don José y don Ignacio Gutiérrez, comerciantes con tienda en la calle Bodegones, tenían en su poder 3,500 pesos solo de los intereses pagados por los acreedores de Bartolomé (AGN GO-BI 5 L. 186 Exp. 1105 1810 f. 57r).

\section{El "bastísimo comercio” al que se dedica: la carrera de Quito}

En 1795, ante las dificultades económicas que empezaron a presentarse para los comerciantes limeños y la negativa a su pedido de ascender al grado de coronel de milicias, Bartolomé de Mesa decidió residir en Quito aprovechando los contactos que tenía con comerciantes de esa región. Su decisión fue acertada y, según sus declaraciones, mientras residió en el reino de Quito estuvo muy ocupado encargado de un "bastísimo comercio" que abarcaba desde Cartagena hasta Lima y que realizó por cerca de doce años. En junio de 1806, cuando Bartolomé regresó a Lima, al referirse a la situación de sus 
negocios en Quito señaló que había dejado más de 50,000 pesos en existencias (AGN GO-BI 5 L. 186 Exp. 11051810 f. $29 \mathrm{r}-\mathrm{v})$. Efectivamente, el negocio parecía ir bastante bien de acuerdo con lo que se desprende de la documentación. Sin embargo, no pasaba lo mismo con su matrimonio.

Con el paso de los años y la postergación del retorno de Bartolomé a Lima, el matrimonio se fue deteriorando. En 1805, Bernarda presentó una demanda ante el virrey Avilés para que Bartolomé cumpliera la sentencia que señalaba que debía retornar a Lima para hacer "vida maridable" y pasarle una pensión de 96 pesos mensuales. En su alegato, le hizo saber al virrey que desde hacía casi doce años Bartolomé residía en Quito "con un total olvido de su mujer y su familia y de la obligación a que se hiso por santo matrimonio" (AGN GO-BI5 L. 175 Exp. 9261805 f1-f7). De acuerdo con los cálculos de Bernarda, el importe de la deuda por alimentos ascendía a 2.512 pesos. En esa sentencia se le había dado a Bartolomé seis meses de plazo para regresar a Lima, pero él solicitó que se le diese un año de plazo para poder “(...) recoger todos mis intereses regados en la enunciada ciudad de Quito y su provincia en donde he tenido un grueso comercio serca de doze años, y asi mismo concluir barios pleytos de gravedad y de considerables intereses (...)" (AGN GO-BI5 L. 175 Exp. 9261805 f25).

El pedido le había sido concedido, pero al reclamar Bernarda ante el virrey, este revocó la autorización para que pudiese permanecer un año en Quito y le dio de plazo quince días para solucionar todos sus asuntos y retornar a Lima.

Gabriel Avilés y del Fierro, el mismo que había tenido el puesto de gobernador del presidio del Callao y cuya opinión 
impidió que Bartolomé obtuviese el grado de coronel, había sido nombrado virrey del Perú en $1801 .{ }^{18}$ Cuatro años después, en junio de 1805, estando informado del reclamo presentado por Bernarda, pidió al presidente de la Audiencia de Quito que obligasen a Bartolomé a retornar a Lima en el plazo de quince días. Ante este abuso, Bartolomé le hizo llegar una carta al rey por intermedio de sus apoderados en Madrid en la que le hace saber que estaba abandonando el reino de Quito contra su voluntad.

"Don Bartolome Mesa Yupanqui vecino y del comercio de Lima y al presente residente en este Asiento de Ambato por enfermedad, estando de transito por Guayaquil por orden de vuestro presidente de Quito por ruego y encargo de vuestro virrey de Lima, sin rebocar el poder que le tengo conferido al procurador general de naturales Pablo Garcia digo: que una noticia de que dicho vuestro virrey me negó por auto un ańo de termino que le pedi para regresarme a desa ciudad de los reyes, a irme con mi mujer, en la qual podria recoger todos mis intereses regados en la enunciada ciudad de Quito y su provincia, en donde ha tenido un grueso comercio serca de doze años, y asi mismo concluir barios pleytos de gravedad y de considerables intereses ...”. (AGN GO-BI5 L. 175 Exp. 9261805 f. 25).

18 Trigésimo séptimo virrey del Perú. Militar de carrera en la rama de caballería, llegó al Perú en 1767 para organizar esa rama de las milicias. Fue enviado a combatir la rebelión de Túpac Amaru II y asumió la dirección del ejército de pacificación en 1782. Ese mismo año fue nombrado gobernador del presidio del Callao, cargo en el que permaneció hasta 1796 en que fue nombrado gobernador de Chile. En 1799 fue nombrado virrey en Río de la Plata y al año siguiente virrey del Perú. Asumió el cargo en 1801 y lo mantuvo hasta 1806. Permaneció en el Perú hasta 1810 en que decidió retornar a España, pero falleció en el trayecto. Durante su gobierno la comandancia general de Maynas retornó al Perú (1802) (Tauro del Pino, 1966, t. I, pp. 139-140). 
Le hace saber al rey que la poderosa razón por la que debía permanecer en Quito era que se encontraba en medio de un juicio por el pago de una cuantiosa deuda que había perdido en una primera instancia y le habían embargado todas sus mercancías y rematado parte de ellas. Y que el virrey Avilés conocía de su situación:

(...) siendo asi que le constaba, que yo no me allava expedito que no era baxo ni sin destino sino que estaba con jiro de un bastisimo comercio desde serca de 12 años antes desde Cartagena hasta Lima, que tenia muchisimas dependencia regadas, varios pleitos y sobretodo de allarme arraigado judicialmente de dicho su amigo Bermudez, y retenidos todos mis efectos sin poderlos jirar francamente donde me tubiese mas cuenta, sino que me beyia sujeto a benderlos realmente en la ciudad a los que fuera a comprar a mi tienda (...). (AGN GO-BI5 L. 175 Exp. 9261805 f. 26-27). ${ }^{19}$

El virrey no tuvo en cuenta estos hechos -se quejaba Bartolomé- y con el "pretesto de que fuese a unirme con mi mujer" pidió al gobierno de Quito que me hiciesen salir en quince días. ${ }^{20}$ Esta situación lo había puesto en una situación económica muy delicada.

Con el plazo tan corto como los quince días que le había dado el virrey, a Bartolomé no le quedó otra salida que iniciar su retorno a Lima, a donde llegó a fines de 1806. Tan pronto se estableció en la ciudad se reincorporó al comercio limeño, pero mantuvo estrechos vínculos con los comerciantes quite-

19 Esta afirmación de que el virrey sabía que no era "baxo ni sin destino" probablemente la señala para mostrar que los argumentos utilizados por Avilés en 1795 eran totalmente falsos.

20 El documento enviado por el virrey Avilés llegó a la presidencia de Quito el 6 de julio de 1806. 
ños, algunos de los cuales quedaron a cargo de sus negocios en la región.

El retorno a la ciudad no mejoró la relación con su esposa. Bernarda le exigió el pago inmediato de la deuda que le tenía por alimentos y solicitó al superior gobierno que se le permita tomar el dinero de las mercancías que tenía Bartolomé en la aduana. Isidro Vilca, abogado de Bartolomé, logró impedirlo presentando un escrito en el que señala que Bernarda ha recibido 13.000 pesos a cuenta de su dote y que existe un recibo que lo comprueba, aunque ella no quiera reconocer el pago (AGN CA-JO1 L. 153, Exp. 28211807 f.1). Paralelamente, Bartolomé decide abrir un juicio ante el alcalde ordinario de Lima para que Pablo Ramírez Arellano, representante de Bernarda, le entregue el testimonio de la escritura de la dote (AGN RE/PS L. 153 Exp. 2821 1807). Ante esta respuesta, Bernarda decide presentar la demanda de divorcio en 1808 (AGN GO-BI5 L. 181 Exp. 10031808 f.15). Inmediatamente, Bartolomé presenta una petición al virrey Abascal en la que solicita que la causa que le sigue su mujer para que la autoricen a retener unos baúles con mercadería de Castilla que acababan de ingresar al puerto del Callao se remita al Tribunal del Consulado de Lima (AGN R.A. C.C. L. 181 Exp. 1003 1808). Es evidente que esperaba que el tribunal impidiese que los baúles pasasen a poder de Bernarda. El fuero del

130 tribunal debía protegerlo por ser uno de sus miembros, como efectivamente sucedió. Su esposa no logró quedarse con la mercadería, pero Bartolomé tampoco; los baúles quedaron retenidos en la aduana del puerto hasta 1818. Este resultado poco favorable a sus intereses sumado a los acontecimientos que tendrán lugar en la metrópoli y su repercusión en el territorio americano lo llevaron por un camino muy distinto del que había transitado hasta ese momento. 


\section{En pos de la autonomía}

En este complicado contexto en el que se encontraba su vida familiar y sus negocios, llegó a la ciudad la noticia de la invasión de Espańa por Napoleón Bonaparte y del establecimiento de una Junta Central en Madrid para resistir la invasión francesa en 1808. Estas noticias preocuparon hondamente a la población del virreinato, por lo que fueron objeto de una amplia discusión. En enero del año siguiente, la junta establecida en Sevilla decretó que los territorios americanos no eran colonias, sino parte integral del territorio español y, por lo tanto, con derecho de representación. Este hecho generó que en distintas partes de los territorios americanos, los pobladores se decidiesen por el autogobierno y empezaran a organizarse en juntas de gobierno. La primera de estas juntas se estableció en La Paz en julio de 1809 seguida de Quito al mes siguiente. Ambas juntas asumieron el gobierno en nombre del rey, a quien se declararon fieles (Chust, 2007). ${ }^{21}$

Las noticias del establecimiento de juntas de gobierno en La Paz y Quito llegaron a Lima y fueron ampliamente discutidas por la población. En particular, para Bartolomé de Mesa lo que estaba pasando en Quito revestía especial importancia. La situación de sus negocios en esa ciudad continuaba sin

21 No existe consenso si esta declaración de fidelidad al rey fue verdadera o parte de una estrategia para conseguir sus fines independentistas. Manuel Chust y el grupo de historiadores, cuyos trabajos forman parte del libro 1808: la eclosión juntera en el mundo hispánico, consideran que en 1808 los criollos no tenían razones para lanzarse a la insurgencia, por el contrario, los grupos de poder americanos temían las consecuencias políticas y económicas que un distanciamiento de la metrópoli podría acarrear, por eso, siempre se manifestaron fieles a la Corona española (2007, pp. 11$50)$. 
solución, por lo que permanecía vinculado con comerciantes de la región. Al igual que otros habitantes de la ciudad, Bartolomé formaba parte de una tertulia que se reunía para discutir temas relacionados con la realidad del país. El grupo estaba conformado por personas dedicadas a diversas actividades económicas, pero todas interesadas en lo que estaba sucediendo en la metrópoli y en las consecuencias que estos hechos podían tener en el ámbito local. Las reuniones tenían lugar en el estudio del abogado Mateo Silva, en los portales de la plaza mayor. Además de Mateo, integraban el grupo su hermano Remigio Silva, dedicado al comercio; Antonio María de Pardo, gallego que compartía el estudio con Mateo; José Antonio Canosa, también gallego; José María García, empleado en el ramo de las suertes; el subteniente José Bernardo Manzanares; el cadete don José Gaete, Juan Sánchez Silva, comerciante; Pablo Zorrilla y José Santos Figueroa. La vinculación de Bartolomé con los miembros del grupo probablemente se dio a través del próspero comerciante Toribio Silva Marín, padre de Mateo y Remigio, sindicados en un primer momento como los líderes del movimiento. ${ }^{22}$

Luego de los sucesos de Quito, el grupo empezó a discutir la posibilidad de establecer una junta de gobierno en Lima para impedir que los planes del virrey Abascal de convertir a Lima en el centro de la contrarrevolución pudiesen tener éxito 132 (Mendiburu, 1887, t. VII, p. 345; Vicuña Mackenna, 1971, pp. 78-80). A pesar de lo decretado por la junta en Sevilla, la

22 Remigio fue liberado luego de un año gracias a las arduas gestiones realizadas por su padre. Mateo no corrió la misma suerte, la acusación en su contra permaneció y fue condenado a diez años de prisión en la cárcel de Bocachica, en la que permaneció solo siete ańos porque enfermó y fue trasladado al hospital de Bellavista, donde falleció en 1816. 
idea de establecer un gobierno autónomo en la capital chocaba frontalmente con la posición del virrey Abascal, que consideraba que la formación de juntas en América era el paso previo a la declaración de independencia. Las reuniones en el estudio de Silva pronto llegaron a los oídos del virrey Abascal, que los acusó de conspiradores y de estar vinculados con los insurgentes de Quito. La noche del 26 de setiembre de 1809, los acusados fueron trasladados a la cárcel de corte, conocida como el infiernillo (Mendiburu, 1887, t. VII, p. 345).

La acusación contra Bartolomé de Mesa fue especialmente peligrosa porque fue acusado de mantener correspondencia con los insurgentes de Quito. En otras palabras, se le responsabilizaba de ser el nexo con los rebeldes del norte. Los descargos de Bartolomé no llegaron a ser registrados, pues falleció cuando se le estaban tomando sus declaraciones (AGN GO-BI 5 Leg. 186 Exp. 11051810 f.4r).

En qué medida la acusación contra Bartolomé de Mesa y el resto del grupo fue cierta es materia de discusión entre los estudiosos de este periodo. Las investigaciones más recientes señalan que la conspiración de los hermanos Silva, como se le conoce, formó parte de una serie de tertulias que tuvieron lugar en Lima, en las que grupos de limeños de tendencia liberal descontentos con el papel secundario deparado a los americanos buscaron la manera de que se estableciese una junta autonomista en Lima (Peralta, 2007). Este objetivo se habría fortalecido luego de la llegada del virrey Abascal al poder aprovechando el contexto de la invasión napoleónica a España y la organización de juntas de gobierno en la metrópoli.

Las motivaciones personales de Bartolomé de Mesa para participar en la conspiración eran varias. Los reveses en su activi- 
dad comercial de los últimos años debido a la prepotencia del virrey Avilés lo llevaron a cuestionar el gobierno virreinal; en varias cartas dirigidas al rey le hace saber las decisiones abusivas de esa autoridad y el incumplimiento de los derechos que la Corona había otorgado a las élites indígenas (AGN GO-BI5 L. 175 Exp. 926 1805; Alaperrine, 2007, pp. 285286). Por otro lado, era un hombre culto, ilustrado, conocedor de las ideas que circulaban en Europa y de los cambios a favor de los americanos que se estaban discutiendo en la metrópoli, por lo que es muy probable su participación para establecer en Lima un gobierno autónomo, así como su vinculación con los rebeldes de Quito. Los organizadores y líderes de la conspiración quiteña fueron los abogados Juan de Dios Morales y Manuel Rodríguez de Quiroga apoyados por miembros de la nobleza quiteńa y de la alta jerarquía de la iglesia (Büschges. 2007, pp. 247- 251; O’Phelan, 2014, pp. 68-69). Entre los nobles implicados estaban los dedicados al comercio con los que Bartolomé pudo haber tenido relación y serían los que lo mantenían informado sobre la situación en la región, fueron probablemente los mismos que le hicieron llegar las noticias sobre las medidas que el gobierno autónomo podría tomar a favor de sus intereses económicos, como la creación del consulado de comercio que permitiría a los comerciantes tener su propio tribunal de justicia en reemplazo de la antigua corporación de mercaderes que no tenía esta atribución (Büschges, 2007, p. 253). ${ }^{23}$ Un tema de especial

23 La nobleza quiteńa estaba vinculada principalmente a la propiedad de la tierra. Sin embargo, hubo importantes familias entre los conjurados dedicadas a la actividad comercial, como la de Juan Pío Montúfar, segundo marqués de Vista Alegre y presidente de la junta. Su hermano, Pedro Montúfar, fue el mercader más importante del periodo colonial tardío (Büschges, 2007, p. 114). 
importancia para los quiteños y en especial para los dedicados a la actividad comercial era conseguir el control del puerto de Guayaquil, que era el puerto de Quito, y que desde 1803 había pasado nuevamente al control del virreinato del Perú (O'Phelan, 2014, p. 75). El problema para los rebeldes era que no habían conseguido el apoyo de la gobernación de Guayaquil. Más bien, en esta gobernación como en la de Popayán y Cuenca, se organizó inmediatamente la resistencia a la junta quiteńa y la dejaron aislada, lo que contribuyó a su corta duración. Cuando llegó el ejército enviado por el virrey Abascal, la presidencia de la junta había pasado a manos de un realista moderado, quien finalmente entregó su cargo al anterior presidente de la Audiencia (Büschges, 2007, p. 254).

La participación de Bartolomé de Mesa en la conspiración se explica por la postergación y el abuso del que había sido objeto, pero también porque era un hombre interesado en la realidad del Perú y conocedor de las ideas ilustradas que cuestionaban el orden establecido, interés que compartía con varios de los integrantes del grupo como los hermanos Silva y Antonio María de Pardo. ${ }^{24}$ Su participación en la conspiración debió ser considerada importante por la red de contactos que manejaba y que se extendía a diversas regiones del virreinato. ${ }^{25}$ Los comerciantes eran siempre un elemento

24 Bartolomé era lector del Mercurio Peruano, como lo demuestra Alaperrine-Bouyer (2007, p. 283), aunque no figura en la lista de suscriptores del periódico.

25 Antes de partir a Quito, Bartolomé conoció a comerciantes procedentes de diversas regiones del virreinato que compraban mercancías en su almacén para trasladarlas a Quito (Mariano de Cadena, Juan de Cadenas, Manuel Zeballos), Cajamarca (Manuel Porras), Lambayeque (José Ormechea, Gabino del Pozo), Yauyos (Pedro Montalván), Pasco (Cosme Jiménez), Huamanga (Ilario Gómez, Carlos Ruiz), Huánuco (Manuel 
valorado en toda conspiración porque los contactos que manejaban permitían que el grupo estuviese informado acerca de lo que estaba ocurriendo en estas regiones y en caso de ser necesario podían difundir los objetivos del movimiento y conseguir apoyo. Por ese mismo motivo, debió ser considerado peligroso para las autoridades coloniales, que no dudaron en revisar su correspondencia para encontrar vínculos con los rebeldes quiteños. ${ }^{26}$

Por otro lado, su cercanía a las élites indígenas de la ciudad debió ser un elemento valorado por los conspiradores, pero considerado peligroso para las autoridades. Como se vio líneas arriba, Bartolomé había actuado como benefactor de la nación índica en la difícil coyuntura posterior a la rebelión de Túpac Amaru II, por lo que el cabildo de indios de la ciudad le otorgó un poder para que represente los intereses de la nación índica tanto en la ciudad de Lima como ante el consejo de la corte de Madrid en 1791 (AGN Fáctica 1791). En el tiempo que residió en Quito, mantuvo contacto con las autoridades indígenas de la ciudad y los procuradores de naturales se encargaron de velar por sus intereses en Lima. A su retorno, ante las difíciles circunstancias en las que se encontraba por la forma abrupta como había dejado sus negocios en Quito, asumió su defensa el procurador de naturales

Beraún, Manuel Falancha, José Narbar), Chancay (Hermanos Bonavia), Jauja (Isidro Galarza), Arequipa (Antonio Carbajal, Rafael Calatayud, Manuel Dionisio Neira), Cuzco (Mateo Lamas, Carlos Ruiz, Juan Palomino) y Moquegua (Juan Pascual Chocano) (AGN PN No 584 1788/89; No 585 1790/91; No 586 1792/93).

26 Hasta el momento, no he encontrado documentación que señale puntualmente qué información se encontró en la correspondencia que le fue confiscada. El hecho de que muriese cuando le estaban tomando sus declaraciones dificulta aún más acceder a esa información. 
Isidro Vilca con quien lo unía una antigua amistad (AGN GO-BI5 L.175 Exp. 926 1805; AGN GO-BI5 L.181 Exp. 1003 1808).

Bartolomé de Mesa falleció repentinamente en la cárcel de corte cuando le estaban tomando sus declaraciones (AGN GO-BI 5 L.186 Exp.1105 1810). Fue declarado pobre de solemnidad, debido a la situación en la que se encontraba al morir y fue trasladado al Sagrario. Isidro Vilca, procurador de naturales, que actuaba como su abogado y encargado del manejo de sus bienes, consiguió autorización para que el depositario general le entregase 500 pesos de los bienes que le habían confiscado para cubrir los gastos de los funerales y las misas. De acuerdo con Vilca, estos debían hacerse "con toda la solemnidad y pompa que pudo hacérsele a la persona más distinguida de esta capital". Los funerales tuvieron lugar en la iglesia de Santo Domingo. Su cuerpo iba vestido con una rica mortaja, indicativo de la calidad que detentaba Bartolomé de Mesa Túpac Yupanqui y fue acompañado con los mejores parámetros de plata. Después de la celebración de las misas respectivas, el cuerpo fue sacado de Santo Domingo por la comunidad dominica acompañado con la cruz de la catedral y con asistencia de los naturales residentes en la ciudad (AGN GO-BI 5 L. 186 Exp. 11051810 f.3v-4r). El tipo de celebración fúnebre llevada a cabo evidencia que Bartolomé de Mesa, a pesar de su decadencia económica, seguía manteniendo su prestigio dentro de la comunidad indígena de la ciudad de Lima.

\section{A modo de conclusión}

El estudio de la trayectoria de Bartolomé de Mesa permite conocer que las decisiones que tomó para establecer, expan- 
dir y proteger sus negocios fueron semejantes a las de sus pares pertenecientes a las élites criolla y española de la época. De Mesa, al igual que otros comerciantes del periodo, inició sus negocios con el apoyo de miembros de su familia, luego se casó con una mujer de fortuna que aportó con su dote a fortalecer el negocio, habilitó con dinero y productos a comerciantes de diversos lugares del virreinato y diversificó sus actividades invirtiendo en tierras y propiedades urbanas y alcanzó un alto grado en la milicia indígena. Desde su perspectiva, como miembro de la nobleza indígena, el grado de coronel era lo único que lo separaba de ocupar la misma posición que los nobles españoles dedicados al comercio. El grado de coronel debía proporcionarle la posición que por su poder económico y méritos realizados a favor de la Corona le correspondía y que le permitirían alcanzar posiciones de mayor poder, como llegar a ser nombrado cónsul en el Tribunal del Consulado. En 1794, ante las dificultades económicas que empezaron a presentarse para los comerciantes limeños y el revés sufrido en su búsqueda por conseguir el grado de coronel, decidió establecerse en Quito. Esta región no le era ajena, pues desde el inicio de su carrera había tenido contactos con comerciantes quiteńos. Los negocios que realizó una vez establecido en Quito fueron muy ventajosos, por lo que permaneció doce ańos, al cabo de los cuales fue obligado a regresar viéndose perjudicado económicamente, pero mantuvo el contacto con sus pares quiteños.

La invasión francesa en la metrópoli y el establecimiento de juntas de gobierno en La Paz y Quito lo llevaron a involucrarse directamente para conseguir el establecimiento de una junta de gobierno en Lima que permitiese a las élites locales obtener la autonomía necesaria para el manejo de sus asuntos. 


\section{Agradecimiento}

Deseo agradecer los comentarios y la información brindados por Cristina Mazzeo de Vivó y Francisco Quiroz a la primera versión de este texto. Así como al lector anónimo, cuyos cometarios permitieron enriquecer el texto. 


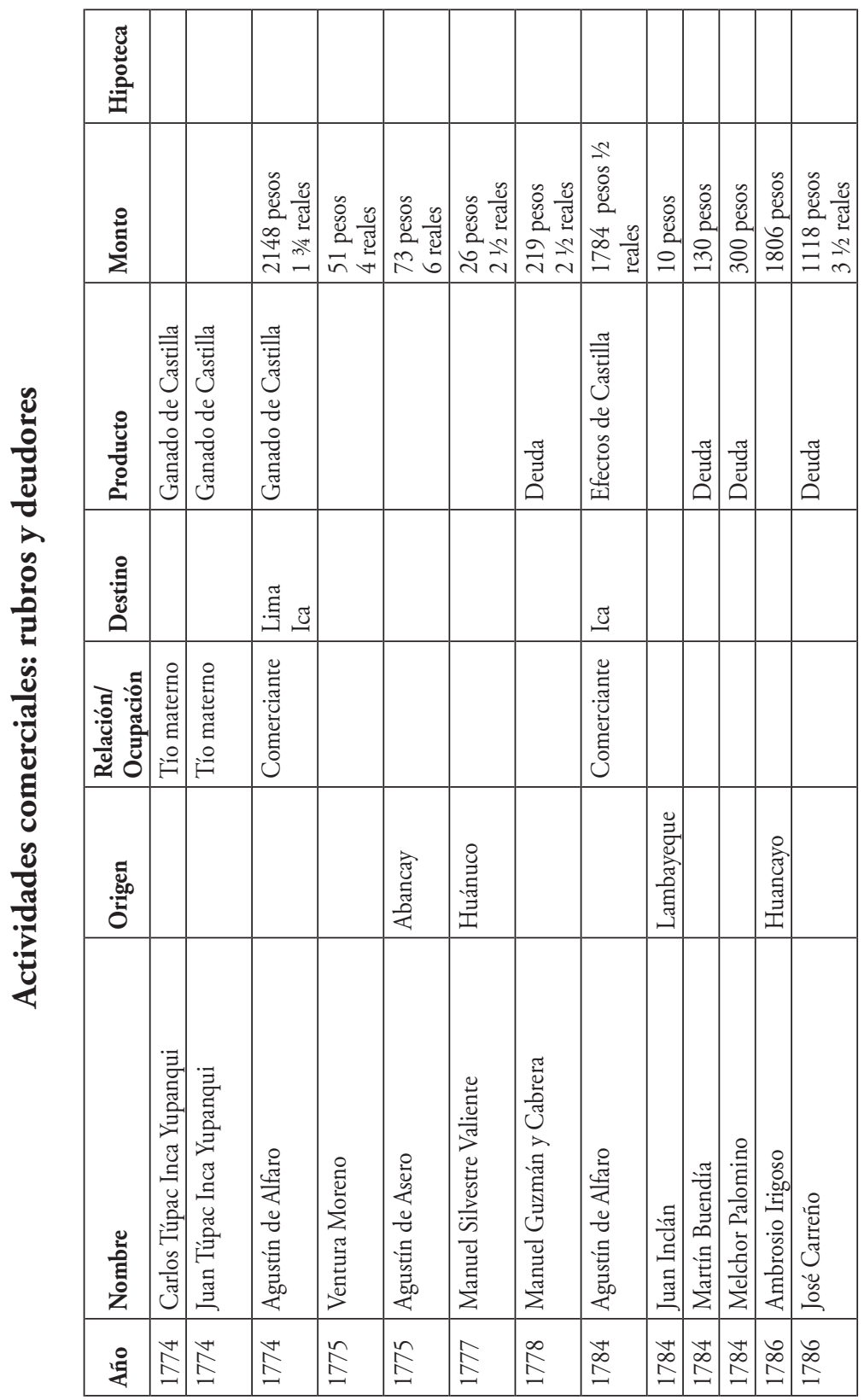




\begin{tabular}{|c|c|c|c|c|c|c|c|c|c|c|c|c|c|}
\hline 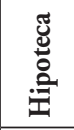 & & & & & & & & & 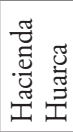 & & 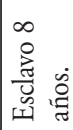 & & \\
\hline 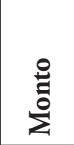 & 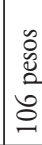 & 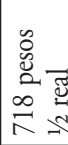 & 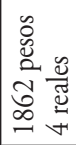 & 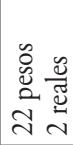 & $\begin{array}{c}0 \\
0 \\
\vdots \\
\vdots \\
N \\
N\end{array}$ & 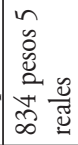 & 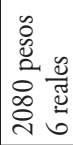 & 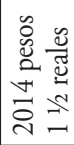 & 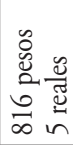 & 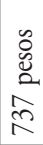 & 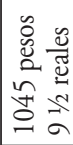 & 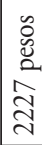 & 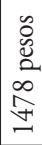 \\
\hline 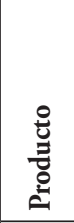 & 章 & 苛 & טٓ & & & صَّ & 泀 & 苞 & 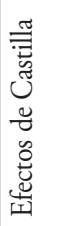 & 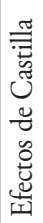 & 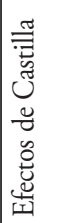 & 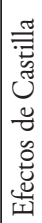 & 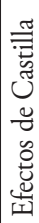 \\
\hline 苞 & & & & & & & & & 忞 & 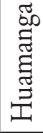 & & & \\
\hline 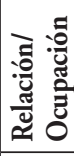 & & & & & & & & & & 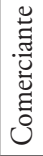 & & 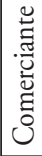 & \\
\hline 总 & & 胥 & & U્త్ & 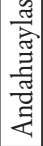 & & & & 忞 & $\stackrel{\ominus}{\Xi}$ & & $\stackrel{\mathfrak{Z}}{:}$ & 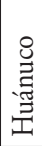 \\
\hline है & 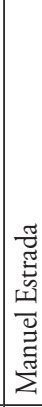 & 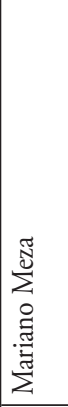 & 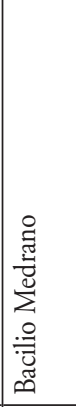 & 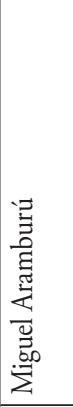 & 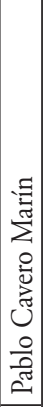 & 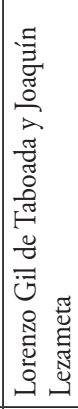 & 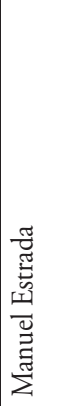 & 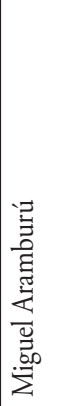 & 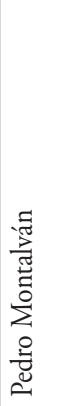 & 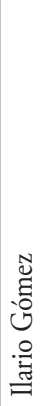 & 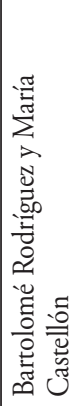 & 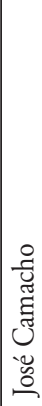 & 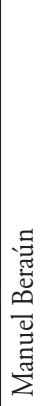 \\
\hline 是 & $\begin{array}{l}\circ \\
\stackrel{2}{=} \\
=\end{array}$ & 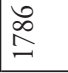 & 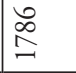 & $\stackrel{\infty}{\perp}$ & $\begin{array}{l}\infty \\
\infty \\
-\end{array}$ & $\stackrel{\infty}{\stackrel{\infty}{\beth}}$ & $\stackrel{\infty}{\stackrel{\infty}{\beth}}$ & $\stackrel{\infty}{\stackrel{\infty}{\beth}}$ & 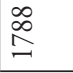 & $\begin{array}{l}\infty \\
\stackrel{\infty}{\beth} \\
\end{array}$ & $\begin{array}{l}\infty \\
\stackrel{\infty}{\beth} \\
\end{array}$ & $\begin{array}{l}\infty \\
\stackrel{\infty}{\beth} \\
\end{array}$ & $\begin{array}{l}\infty \\
\stackrel{\infty}{\beth} \\
\end{array}$ \\
\hline
\end{tabular}




\begin{tabular}{|c|c|c|c|c|c|c|c|c|c|c|c|}
\hline 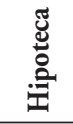 & & & & & & & & & & & \\
\hline 总 & 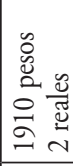 & 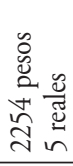 & 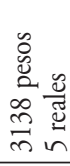 & 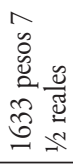 & 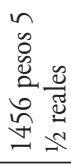 & 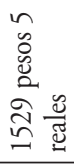 & 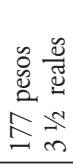 & 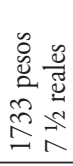 & 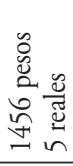 & 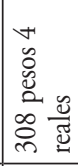 & 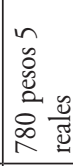 \\
\hline 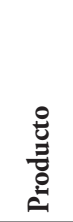 & 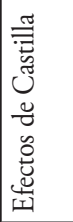 & 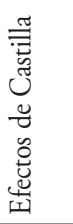 & 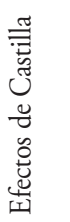 & 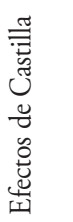 & 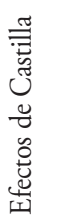 & 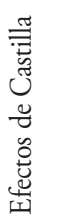 & & $\begin{array}{l}\frac{\pi}{\vec{U}} \\
\stackrel{\tilde{D}}{0}\end{array}$ & 节 & 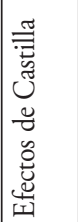 & 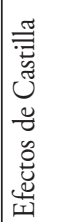 \\
\hline 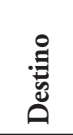 & 䒿 & & 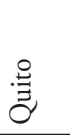 & 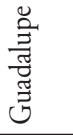 & 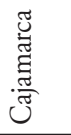 & & & & & & 息 \\
\hline 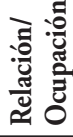 & & & & & & & & & & & \\
\hline 㤩 & $\stackrel{\mathscr{Z}}{\exists}$ & $\stackrel{\mathbb{Z}}{\Xi}$ & $\stackrel{\mathscr{g}}{\Xi}$ & 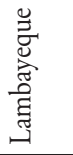 & $\stackrel{\Xi \Xi}{\exists}$ & $\stackrel{\widetilde{\Xi}}{\Xi}$ & 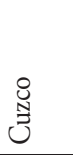 & & & & 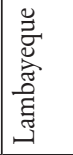 \\
\hline ڤ̆ & 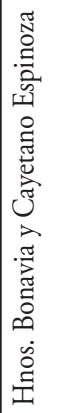 & 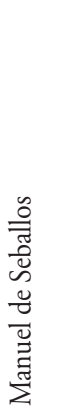 & 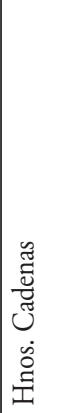 & 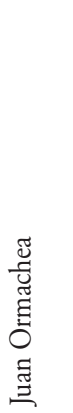 & 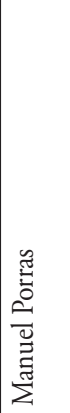 & 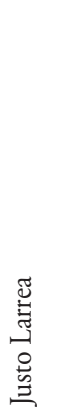 & 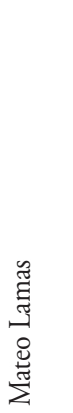 & 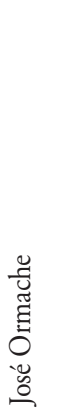 & 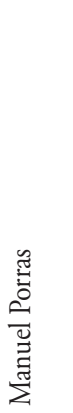 & 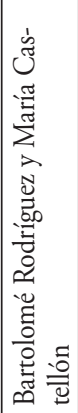 & 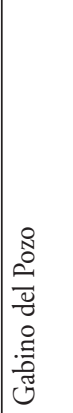 \\
\hline 运 & $\begin{array}{l}\infty \\
\stackrel{\infty}{\beth} \\
\end{array}$ & $\begin{array}{l}\infty \\
\stackrel{\infty}{\perp} \\
=\end{array}$ & $\begin{array}{l}\infty \\
\stackrel{\infty}{\perp} \\
\end{array}$ & $\begin{array}{l}\infty \\
\stackrel{\infty}{\beth} \\
=\end{array}$ & $\begin{array}{l}\infty \\
\infty \\
\end{array}$ & $\begin{array}{l}\infty \\
\infty \\
\beth\end{array}$ & $\begin{array}{l}\infty \\
\stackrel{\infty}{\Sigma}\end{array}$ & $\begin{array}{l}\infty \\
\stackrel{\infty}{\beth}\end{array}$ & $\begin{array}{l}\infty \\
\stackrel{\infty}{\beth}\end{array}$ & $\stackrel{\infty}{\stackrel{\infty}{\beth}}$ & $\stackrel{\curvearrowright}{\stackrel{\infty}{\beth}}$ \\
\hline
\end{tabular}


Teresa Vergara Ormeño

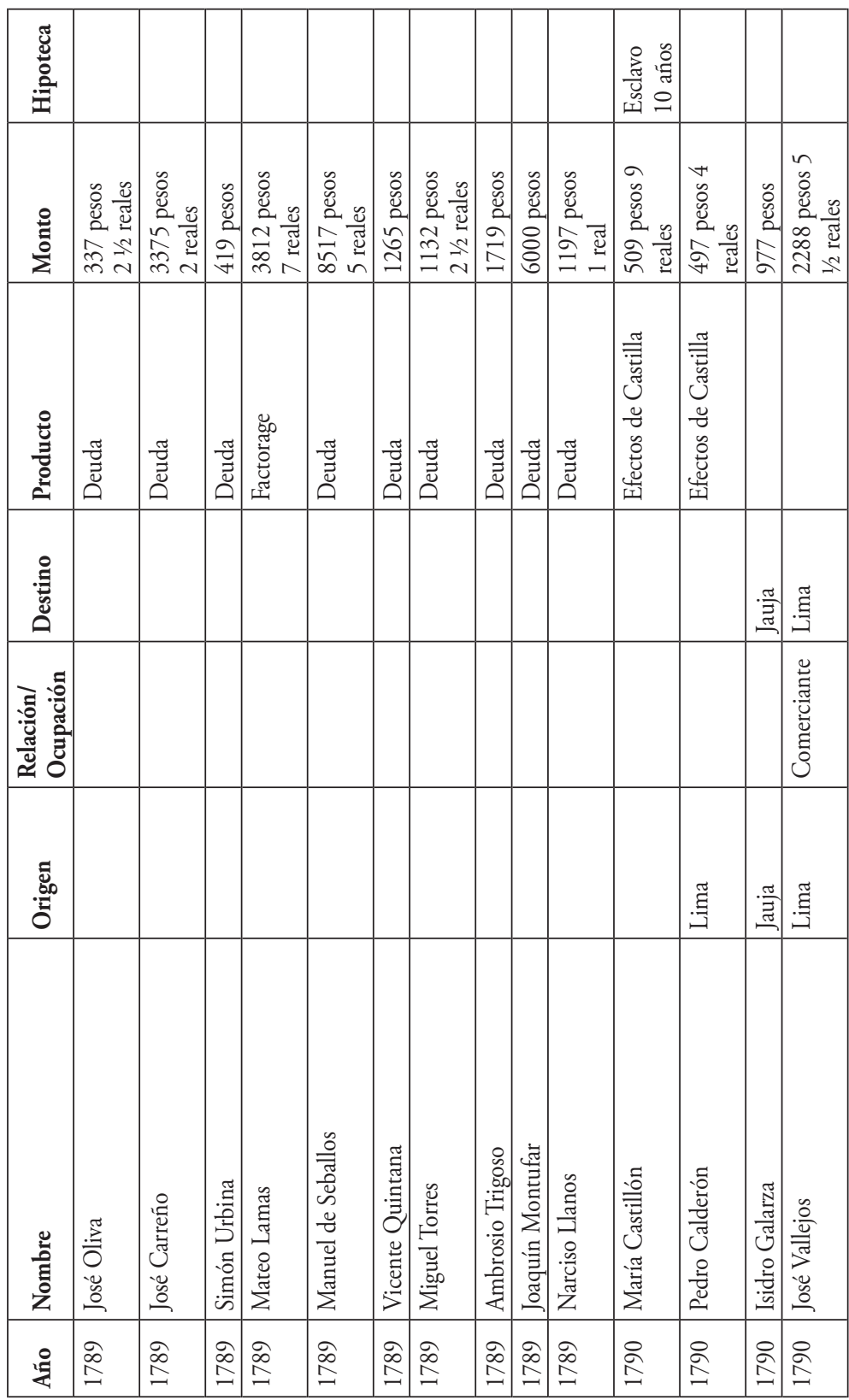




\begin{tabular}{|c|c|c|c|c|c|c|c|c|c|c|c|}
\hline 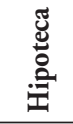 & & & & & & & & & & & \\
\hline 总 & 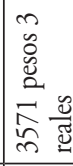 & 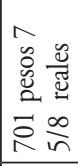 & 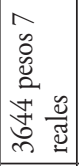 & 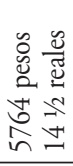 & 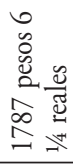 & 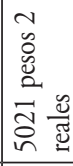 & 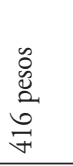 & 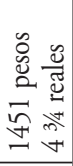 & 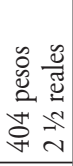 & 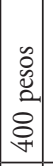 & 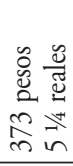 \\
\hline 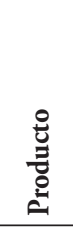 & 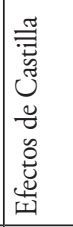 & 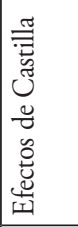 & 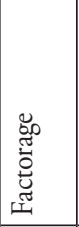 & & 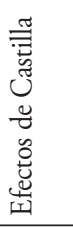 & $\begin{array}{l}\frac{\pi}{\tilde{Z}} \\
0 \\
0\end{array}$ & 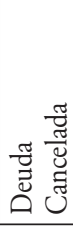 & & & 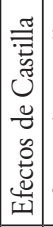 & 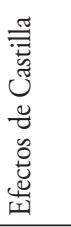 \\
\hline 咅 & 节 & 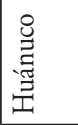 & 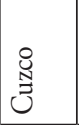 & 苟 & త్రુ & 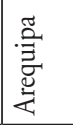 & & 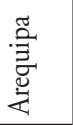 & 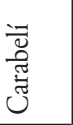 & & 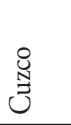 \\
\hline 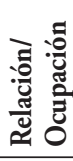 & 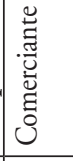 & 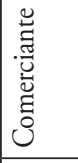 & & & & & & 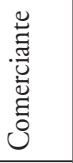 & 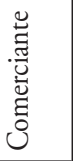 & & \\
\hline 㤩 & 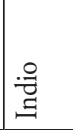 & $\stackrel{\widetilde{\Xi}}{二}$ & $\stackrel{\widetilde{Z}}{\Xi}$ & 苛 & $\stackrel{\widetilde{Z}}{\Xi}$ & 节 & & 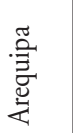 & 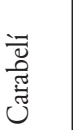 & $\stackrel{\overparen{\Xi}}{\exists}$ & $\stackrel{\widetilde{g}}{\Xi}$ \\
\hline 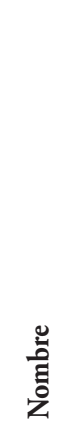 & 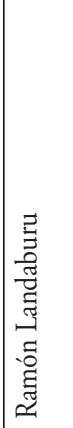 & 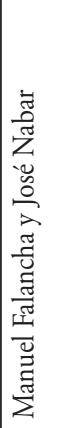 & 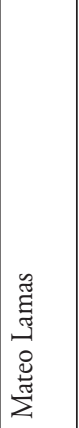 & 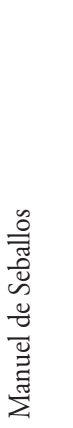 & 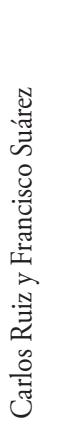 & 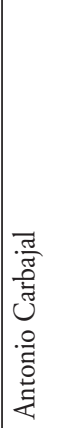 & 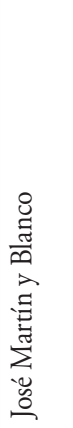 & 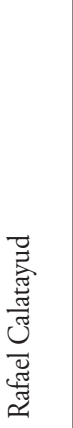 & 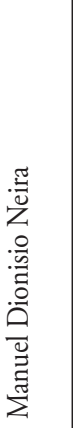 & 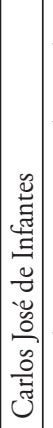 & 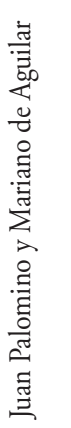 \\
\hline 究 & શ & 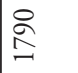 & 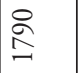 & $\stackrel{\nwarrow}{\nwarrow}$ & 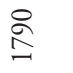 & 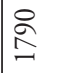 & $\stackrel{શ}{\curvearrowright}$ & $\bar{\Omega}$ & $\bar{\Omega}$ & $\vec{\Omega}$ & $\bar{\Omega}$ \\
\hline
\end{tabular}




\begin{tabular}{|c|c|c|c|c|c|c|c|c|c|c|c|c|c|c|}
\hline 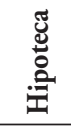 & 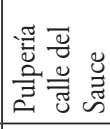 & & & & & & & & & & & & & \\
\hline 竞 & 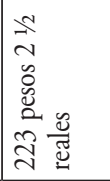 & $\begin{array}{l}0 \\
0 \\
0 \\
0 \\
0 \\
\text { הे }\end{array}$ & 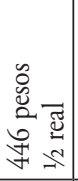 & 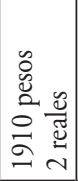 & 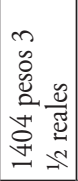 & 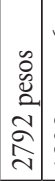 & 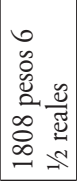 & 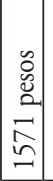 & 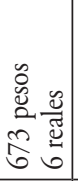 & 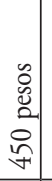 & $\begin{array}{l}0 \\
0 \\
0 \\
0 \\
0 \\
\\
\end{array}$ & 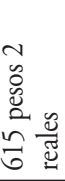 & 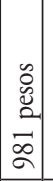 & 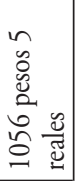 \\
\hline 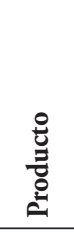 & & 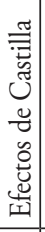 & $\begin{array}{l}\stackrel{\pi}{\vec{z}} \\
\text { ఏ }\end{array}$ & 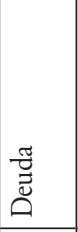 & & 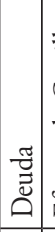 & 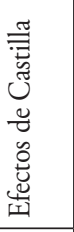 & 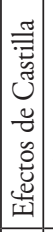 & $\begin{array}{l}\stackrel{\tilde{J}}{\vec{J}} \\
.\end{array}$ & $\begin{array}{l}\tilde{J} \\
\stackrel{\vec{J}}{u} \\
.\end{array}$ & 气ّ̊. & 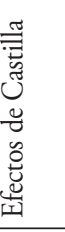 & 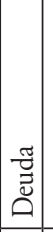 & \\
\hline 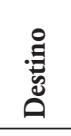 & & & & & 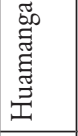 & & & & & & & 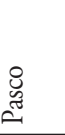 & & \\
\hline 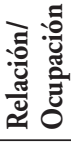 & & & & & & & & & & & & & & \\
\hline . &. & & & & : & 节 & 穿 & & & & & 节 & & 节 \\
\hline हैँ & 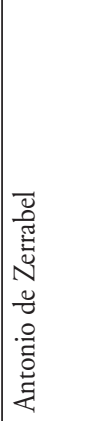 & 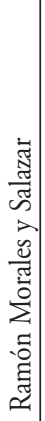 & 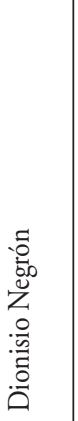 & 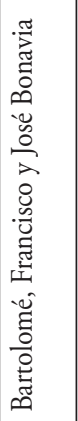 & 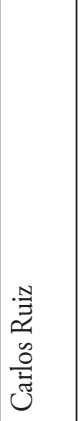 & 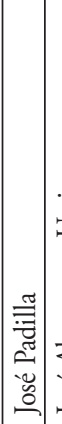 & 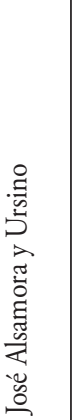 & 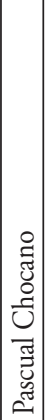 & 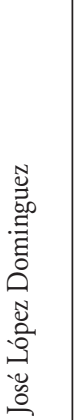 & 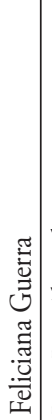 & 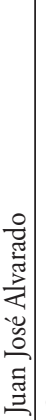 & 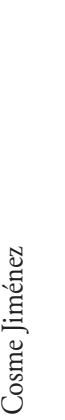 & 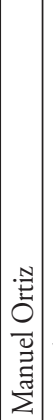 & 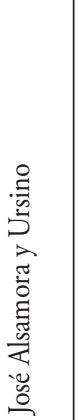 \\
\hline 是 & $\overline{\widehat{\Sigma}}$ & 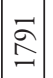 & શ્ & $\bar{\Sigma}$ & $\widetilde{\Sigma}$ & $\approx \Sigma$ & ડૂ & 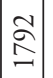 & న̃ & $\widetilde{\Sigma}$ & $\underline{\Sigma}$ & ૂૂ & $\approx$ & 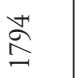 \\
\hline
\end{tabular}




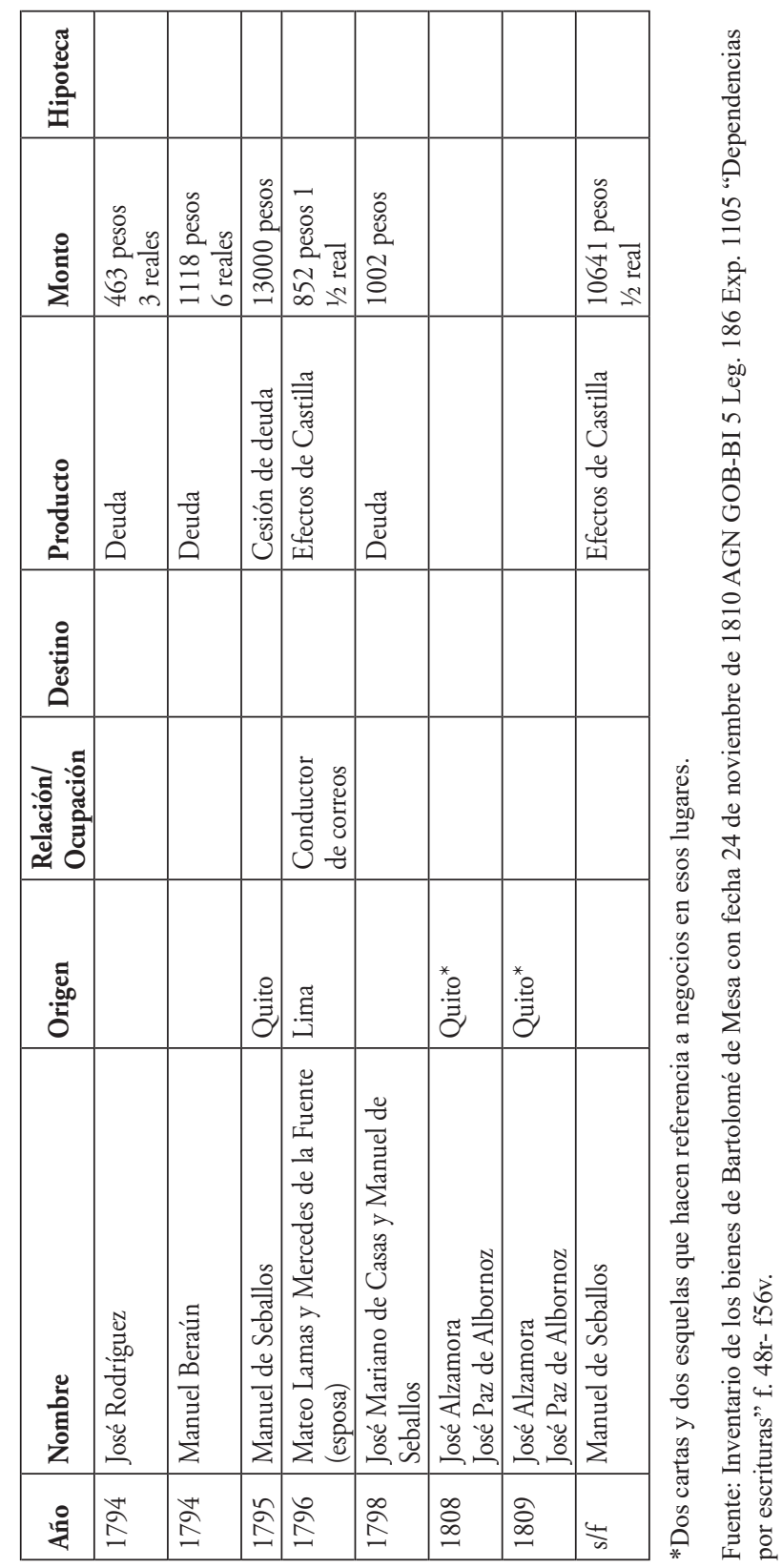


Recibido: 19 de junio de 2017

Aprobaco: 09 de mayo de 2018

\section{Fuentes manuscritas}

Archivo General de la Nación del Perú (AGN)

Secciones:

Superior Gobierno (GO-BI5)

Real Audiencia: Causas Civiles (R.A. C.C.)

Cabildo (CA-ED3)

Cabildo Justicia ordinaria (CA-JO1)

Reales Estancos/Papel Sellado (RE/PS)

Fáctica-Juzgado de Corregidor o Subdelegado del Cercado (Fáctica)

Protocolos Notariales (PN)

\section{Bibliografía}

Alaperrine-Bouyer, $\mathrm{M}$.

(2007) La educación de las elites indígenas en el Perú colonial. Lima: IFEA/IRA/IEP. https://doi.org/10.4000/ books.ifea.652

Arroyo Reyes, C.

(2005) Nuestros años diez. La Asociación Pro-Indígena, el levantamiento de Rumi Maqui y el incaismo modernista. Buenos Aires: Librosenred. 
Büschges, C.

(2007) Familia, honor y poder. La nobleza de la ciudad de Quito en la época colonial tardia (1765-1822). Quito: FONSAL.

Chust, M. (Coord.).

(2007) 1808: la eclosión juntera en el mundo hispano. México: Fondo de Cultura Económica, Fideicomiso Historia de las Américas, Colegio de México.

Cieza de León, P. de.

(2005) Crónica del Perú. El señorio de los Incas. Selección, prólogo y notas de Franklin Pease G.Y. Caracas: Biblioteca Ayacucho.

Cosamalón Aguilar, J.

(1999) Indios detrás de la muralla: matrimonios indigenas y convivencia interracial en Santa Ana (Lima 17951820). Lima: Fondo Editorial Pontificia Universidad Católica del Perú.

Mazzeo de Vivó, C. A.

(1994) El comercio libre en el Perú, las estrategias de un comerciante criollo, José Antonio de Lavalle y Cortés 17771815. Lima: Fondo Editorial Pontificia Universidad Católica del Perú.

Mazzeo de Vivó, C. et al. (Coord.)

(1999) Los comerciantes limeños a fines del siglo XVIII. Capacidad y cohesión de una elite, 1750-1825. Lima: Pontificia Universidad Católica del Perú, Dirección Académica de Investigación.

Mazzeo de Vivó, C.

(2012) Gremios mercantiles en las guerras de la independencia. Perú y México en la transición de la Colonia a la República, 1740- 1840. Lima: Banco Central de Reserva del Perú, Instituto de Estudios Peruanos. 
Mendiburu, M. de.

(1887) Diccionario histórico-biográfico del Perú (t. VII). Lima: Imprenta Bolognesi.

Moreyra y Paz Soldán, M.

(1959) El Tribunal del Consulado. Cuaderno de Juntas (17211727) (t. II). Lima: Editorial Lumen.

O’Phelan Godoy, S.

(1995) La gran rebelión en los Andes. De Túpac Amaru a Túpac Catari. Cuzco: Centro Bartolomé de las Casas.

O'Phelan Godoy, S.

(2014) La independencia en los Andes. Una historia conectada. Lima: Fondo Editorial del Congreso del Perú.

Parrón Salas, C.

(1984) El comercio del Callao con España en vísperas de la emancipación (1797-1808). Cartagena: AREAS.

Perales Murguía, M.

(2004) La ocupación inca en el valle del Cunas (Junín, Perú): una aproximación desde el sitio arqueológico de Arhuaturo. Arqueología y Sociedad (15): 155-172.

Peralta Ruiz, V.

(2007) Entre la fidelidad y la incertidumbre. El virreinato del Perú entre 1808 y 1810. En M. Chust (Coord.), 1808: la eclosión juntera en el mundo hispano. México: Fondo de Cultura Económica, Fideicomiso Historia de las Américas, Colegio de México.

Rodríguez, J. E.

(2007) El reino de Quito, 1808-1810. En M. Chust (Coord.). 1808: la eclosión juntera en el mundo hispano. México: Fondo de Cultura Económica, Fideicomiso Historia de las Américas, Colegio de México. 
Suarez Espinoza, M.

(1995) Comercio y fraude en el Perú colonial. Las estrategias mercantiles de un banquero. Lima: Instituto de Estudios Peruanos, Banco Central de Reserva.

Suárez Espinoza, M.

(2001) Desafios trasatlánticos: mercaderes, banqueros y el estado en el Perú virreinal, 1600-1700. Lima: Pontificia Universidad Católica del Perú, Fondo de Cultura Económica, Instituto Francés de Estudios Andinos.

Tauro del Pino, A.

(1966) Diccionario enciclopédico del Perú (t. I). Lima: Editorial Juan Mejía Baca.

Terralla y Landa, E. de.

(1790) El sol en el mediodia: año feliz, júbilo particular con que la nación indica de esta muy noble ciudad de Lima solemnisó la exaltación al trono de ntro. augustisimo monarca el señor don Carlos IV: En los dias 7, 8 y 9 de febrero de 1790 (...). Lima: Impreso en la Casa Real de Niños Expósitos.

Vicuña Mackenna, B.

(1971) La independencia en el Perú. Buenos Aires: Francisco de Aguirre. 